\title{
Crosswalk: Performing the City as a Learning Experience
}

\author{
Raffaele Rufo
}

\section{Deakin University}

\begin{abstract}
Crosswalk is a site-responsive performance conducted in the middle of a pedestrian crossing in the inner streets of Melbourne and exposed in the homonymous video attached to this article. The performance - an experiment with the duet dance form of Argentine tango - emerged out of a practice-based process of inquiry. My failed attempt to find my tango in the city while finding my place in the city through the tango becomes a drive to explore the nexus between learning and the experience of publicness and defuse the rationalist reliance on the isolated cognitive individual as the key pedagogical agent and target. I argue that, in Crosswalk tango worked (or could have worked) as a reverse public pedagogy through somatic connection not only between dance partners but also with the broader environment. Becoming vulnerable to the otherness of the outside world is one way of promoting diversity and fostering plurality.
\end{abstract}

\section{Keywords}

Argentine tango, site-responsive performance, reverse public pedagogy, dance-based research, dance improvisation, somatic awareness 
This article is concerned with the question of how the everyday publicness of street life in the contemporary city works as a learning experience, and how the figure of the artist as an urban explorer can help uncover some of the conditions, processes and strategies undergirding this particular pedagogical frame. I provide an autobiographical account of my experience of wandering in the central business district streets of Melbourne (CBD) between my arrival in Australia from Italy in October 2015 and that of my family in July 2016. The account builds also upon my PhD practice-based dance and performance research of Argentine tango at Deakin University. Through the combination of exploring the city and inquiring into tango, I have started to develop a site-responsive artistic approach to performance and publicness that is partially and preliminarily captured in the short video attached to the text and based on a spontaneous intervention in the midst of a busy pedestrian crossing (from now on Crosswalk).

My main argument is that the experience of togetherness in public spaces is a complex art of attunement that requires learning to be challenged and even destabilised by otherness without letting it become overwhelming to the point of losing the capacity to cope with the environment. As I walk and I observe, or witness or participate, the city emerges as a reflex of my soul, a public stage, a process of noticing and eventually a creative process that engages my everyday life as well as my dance and through which the evolving lessons of the everyday is taught - to me and through me. Performing (in) publicness involves exploring the ways in which the outside world is affecting me all the time, and how I might notice, resist or yield to what is becoming available outside in an evolutionary process of making sense of what I am sensing through the body. I would like to propose the frame of dance improvisation and, in particular, of Argentine tango-a duet dance form structurally based on the improvised relation between dancers and with their broader context-as a platform and metaphor to explore and describe this process.

The article begins by framing autobiographically my site-responsive performance research in Melbourne CBD. I then introduce Baudelaire's image of the flâneur as a tool to account for my exploration and describe the city wandering practices through which the creative process leading to Crosswalk occurred, as well as the difficulties I have been facing in trying to cope with the chaos of city life. This is followed by some details on Crosswalk as both a creative process and a creative product and by some notes on my aspirations and on the learning lessons ensuing from the experiment. In the last part of the article, I position my practice-based exploration in the theoretical field of public pedagogy and provide some concluding remarks.

\section{The City as Autobiographical Frame}

Working as a mirror of my soul, Melbourne city life began to bring to the surface some of the mysteries of my internal life as a reaction to the unbearably anonymous experience of what was happening outside my skin:

A spectre is haunting the streets of Melbourne.

Seeking his way on the edges of the chessboard,

He travels across opposing dimensions,

Then stops to ponder, in silence.

Fearful, forceful, confused

He crosses people without engagement.

A pawn lost on the margins

Of a disenchanting game.

(March 2005, author's personal diary) 
I had just moved to a new city, a new country, a new hemisphere, on my own, in search of a new life. I was in my late-20s. The experiment failed and, in December 2007, I decided to return to Italy. But the time for a second chance came in October 2015. And the long and thick gap between these two acts in the staging of my personal life as a migrant did make a difference in the way I approached Melbourne the second time. The city began to function more consciously as the stage for a learning process based on participant observation and the recording of sensory raw material. I engaged this new investigative phase as an attempt to make sense of my external sensations of seeing and hearing the overwhelming stimulations of street life. Dwelling in the city as an inquirer between October 2015 and June 2016 provided me with a platform for nurturing an intuitive pedagogical process. I gradually extended and deepened my perception, conception and lived experience of the city as a mirror of my soul and as stage on which I am a participant observer, to allow the frame of creative experimentation to take root. My aim was to pursue discovery and subversion both in the ways I dwell in the city and in the ways I engage with my artistic practice - the duet dance form of Argentine tango. This process ensued in the spontaneous intervention in the midst of a central crosswalk exposed in the video attached and discussed in this article.

\section{The Artist as Urban Explorer}

To describe and interpret my wandering exploration in Melbourne CBD, I will now turn to the figure of the flâneur as the painter of modern life evoked by Baudelaire in an essay dating back to 1863. The flâneur (from the French verb flâner, which literally means to wander around) is not just somebody who observes the city and experiences an actual wandering across its streets, but also a way of seeing, feeling and thinking the things one encounters. Baudelaire (1964) describes the flâneur as the man of the world and of the crowd, as the artist immersed all day in "universal life" with the curiosity of a child, but who is then capable to process and distill the gist of such experience with the stable nerves and the aesthetic craft of a genius. In my reading, Baudelaire's flâneur (associated with the real figure of Constantine Guy, water colour painter and illustrator for French and British newspapers) is a genius who can seamlessly attune to his naturally imaginative consciousness and to the world and who can make sense of publicness through art-making. What is being addressed, and to some degree celebrated by Baudelaire is the evolution of the human spirit facing epochal changes in the patterns of urban life and in self-perception and self-understanding marked by the transition of Paris, London and other major Western European cities into modernity. From a pedagogical perspective, it is worthwhile asking how the contemporary flâneur learns to attune to the world, to the crowd and to the senses in search for inspiration, exchange and fulfilment.

Baudelaire's flâneur sits in the window of a coffee-house, 'mingling, through the medium of thought, in the turmoil of thought that surrounds him ...[he] remembers, and fervently desires, to remember, everything' $(1964$, p. 7$)$ with the attitude of someone who has been on the brink of total oblivion. I find this a powerful image and I would like to use it as a lens to look at my own experience of mingling in the streets of Melbourne through the medium of the senses, in the turmoil of movement surrounding me. Returning to Melbourne after eight years spent in Italy in search for a new life that never came into place made me feel like someone who is convalescent, who has lost his senses and is almost overwhelmed by a desire to feel part of a newly encountered urban fabrics. As in the case of Baudelaire's flâneur, the city, and in particular its central streets, became part of my everyday, as a tangible and metaphorical crossroad between past and future, home 
and school or work, the small picture of private contingency and a larger sensibility and sense of belonging and pursuit.

\section{Wandering as Research}

My process of urban exploration in Melbourne CBD worked mainly through wandering. This, in turn, involved mainly walking, pausing and stopping with the more or less conscious intent to observe, listen, witness and take part. I also engaged in taking photographs and short videos and in recording audios of human and mechanical movements and of the built environment in which they occurred (e.g., the sound of traffic lights and public transport announcements, the feet and voices of pedestrian crossing a street or walking on a sidewalk, the wake of trams and cars and bicycles passing by, etc.). In this multimodal process of participant observation, note-writing and digital recording allowed me to go back to those complex moments I could hardly grasp in-the-moment and helped me frame inputs that would otherwise go unnoticed. Initially, the scope of my inquiry in the CBD was quite broad and unstructured. However, as I got more interested in places of arrival and departure and in masses of bodies moving alongside each other along predetermined trajectories, I reduced my focus to train stations, pedestrian crossings and sidewalks and shifted my attention to situations where I perceived time and space and the energy of movement to be more influenced by the rules and arrangements of the built environment. I started to focus on spaces where I felt it harder to break the grid of mass movement and find a place for improvisation, spaces where living bodies are literally moved by inanimate bodies and by the flow of urban life.

\section{Coping with Chaos}

My autobiographical exploration of Melbourne CBD can be placed in a broader interpretive context by referring to the critical analysis of walking in the city offered by De Certeau (1984) in his famous book on the practice of everyday life. In my reading, De Certeau's work is the work of a flâneur who artfully paints with words, sentences and subtle reasonings the contemporary human condition. De Certeau's exploration of walking in the central streets of Manhattan (New York) is not concerned with what his eyes see when looking down from the heights of a sky tower, but rather with what happens below the threshold at which visibility begins. His aim is to "locate the practices that are foreign to the "geometrical" or "geographical" space of visual, panoptic, or theoretical constructions" and to describe the "metaphorical city "slipping" into the clear text of the planned and readable city' (1984, p. 93). Walking is defined as an elementary way of experiencing this kind of city; pedestrians are portrayed as practitioners whose knowledge of the spaces they are making use of 'is as blind as that of lovers in each other's arms'; the networks of their fragmented, contradictory and intersecting movements are portrayed as writings composing 'a manifold story that has neither author nor spectator' and that, in relation to representation, 'remains daily and indefinitely other' (1984, p. 95).

During the course of my exploration in Melbourne CBD I have tried to place my body into what De Certeau (1984) refers to as the 'textual fabrics' of the city in the making in search for the 'microbe-like, singular and plural practices which an urbanistic system was supposed to administer or suppress' and which create 'a mobile organicity in the environment' (p. 96). However, my focus progressively shifted from what I was observing outside my living body to the alternative paths I myself could take, to how I could try out the available trajectories-yielding to them or resisting them, to how I could follow the myriads of street acts while not being determined by them. As a result, borrowing De 
Certeau's expression, I was left prey to 'the contradictory movement that counterbalance themselves outside the reach of the city ... as a system' (1984, p. 96). I experienced chaos and the inability to be affected by the outer world without frustration. I felt prey to a mass of pervasive and intense stimulations that my unselfconscious bodily awareness was not capable of making sense of. In this experience of rupture, the otherness of the city felt chaotic and unbearable too. I observed and listened to the city as a dehumanised repetition of sound patterns, movement directions, safety codes, spatial arrangements, temporal timetables, etc. A flow of life of which it is hard to find any trace left after it is passed in an ungraspable moment. I rehearsed over and over again the same script: arriving on a train at Flinders St Station, walking across the platform and the foyer, 'touching off' my traveling card, approaching the pedestrian crossing, stopping at the red light, crossing with the green, getting to the other side of the street as quick as possible, reaching the pavement. One thing leading to another thing. A river of people and lights and noises-or of lack thereof-whose water I feel unable to touch. A river that moves me from the outside without asking me where I want to go and why.

De Certeau concludes his chapter on the everyday practice of walking in Manhattan with a heartfelt call that in my view suggests the possibility to interpret and live the city as a transformative learning experience: 'To practice space is thus to repeat the joyful and silent experience of childhood; it is, in a place, to be other and to move toward the other.' (1984, p. 110, emphasis in original)

Returning to my autobiographical narrative, as a migrant, a seeker and a dancer my amorphous body wants to be sensorially and affectively moulded by the encounter with Melbourne-not just metaphorically: I want to have a dance with the city. But how can I let the city teach me how to dance with it? How can I change the frame of my exploration to let this improvised dance of drama and attunement occur? I am wandering in the city looking for who I am, what I can do in this place and for this place, searching for a platform for meaningful living and inspired creating. To find my place in the city is to find an evolving trajectory for my creative impulses, to find a platform for letting my inner drives enter an exchange with a larger relational and imaginative field. But how can I find a way to connect with the chaos I perceive around me, so that I do not become that chaos, so that that chaos can become the frame for my creative investigative practice? The next section turns to these questions by providing a short exegesis of the site responsive dance performance documented in the video attached to this article.

\section{Crosswalk: A Site-Responsive Dance Performance}

Crosswalk is a site responsive performance experiment in Melbourne CBD in the middle of the pedestrian crossing between Flinders Street Station and Swanston Street-arguably one of the busiest in the inner city (see image 1 for a map of Melbourne's central city grid; for an account of the notion and field of site dance performance and site-specific art more in general, see Kaye 2000 and Kloetzel \& Pavlik 2010). 


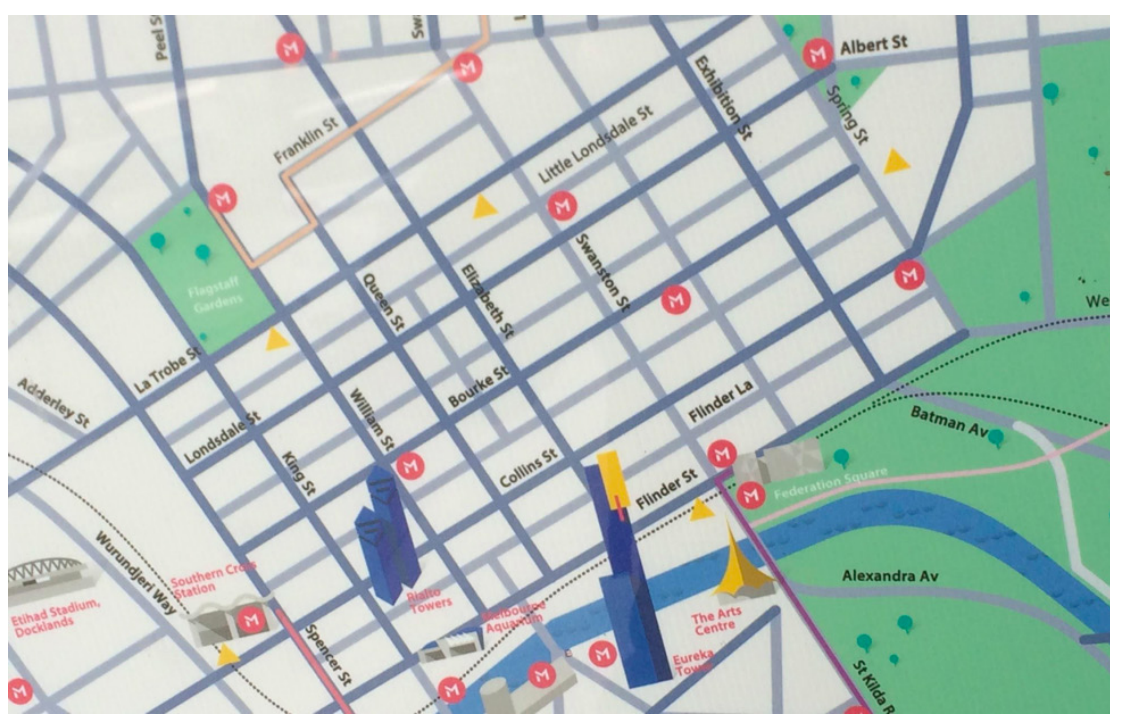

Image 1: Map of Melbourne's central city grid (Melbourne City Council)

The Crosswalk intervention emerged out of countless hours spent observing, taking photos and filming the body movement of people crossing the street in that specific site and listening and recording their voices and the sound loop of the traffic lights. My creative inquiry involved also, and perhaps more importantly, going through that crosswalk over and over again in both directions.

Crosswalk took place on Saturday 30 April 2016 between 6pm and 10pm. The actual dance improvisation lasted for approximatively one hour. I worked with a female dancer and a photographer I had previously met in the Melbourne tango scene. On the morning of the shoot we had met in the city near the performance site to make choices about how to dress, where to position our bodies and the camera and what to do during the experiment. We decided to do one simple thing: to stand right in the middle of the crosswalk-in the safe area between two tram tracks-and to hold each other in a close tango embrace with little or no movements and no music. We would face each other and listen to each other during the two intervals of time going from red lights to green lights and from green lights to red lights. We would focus on breath and balance and we would share some weight with each other to nurture a continuous exchange of sensations via the shared centre in-between the two bodies. We would try to let the movement of the people waiting with the red lights and crossing with the green lights affect our internal worlds but we would not try to interact with pedestrians. I was dressed all in black. My partner was dressed all in white. The photographer was positioned perpendicularly to the trajectory of crossing pedestrians with the goal of capturing the relationship between the movement qualities of our bodies encountering each other in the tango embrace and those of the pedestrians' bodies and of the cars and trams moving around us in the built environment of the city. I personally edited the photos into the video embedded in this article (see next page). 


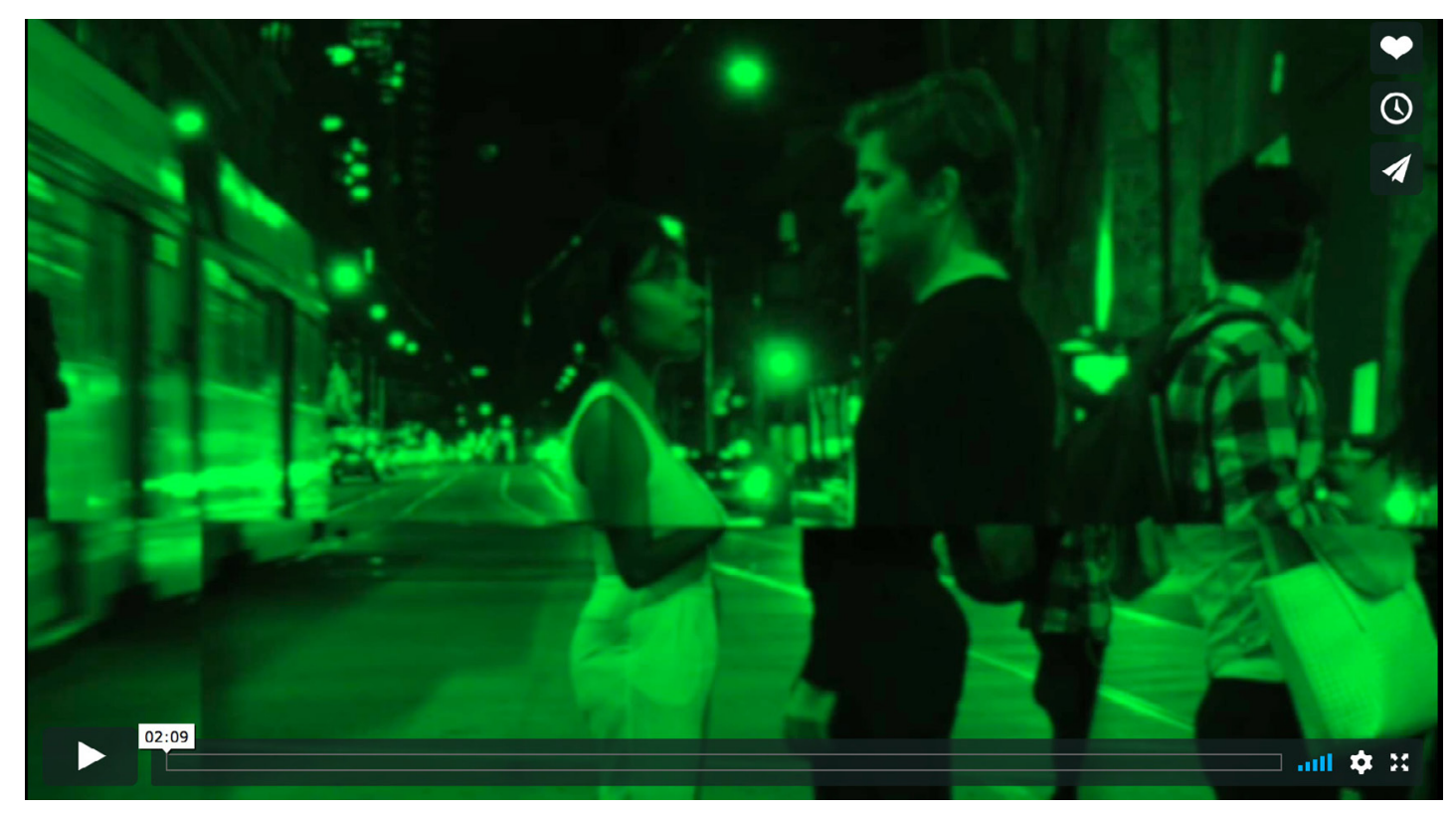

Figure 1: Still from Crosswalk, 2017, by Raphael Rufo (Click on image to visit link and play video)

Along the lines of a creative practice-based research methodology (Nelson 2013), the Crosswalk video can be seen as three things at the same time: a documentation of the event of performing in the middle of a crosswalk in Melbourne CBD; an artistic outcome of dance-based research; and as part of the process of inquiry involving thinking prior and after the event and further audiovisual elaboration of what was experienced and photographed by using editing techniques, site-specific sounds and ad hoc tango music created with these sounds by a professional musician. The video is not just illustrative but it also incorporates insights expressed through images and sounds that might not otherwise be passed on to the reader. This is aligned with the notion of tacit knowing expressed by Polanyi (2009), according to which knowledge should be reconsidered 'starting from the fact that we can know more than we can tell' (p. 4).

\section{Why Crosswalk?}

From an autobiographical perspective, I engaged in the Crosswalk performative experiment, right in the middle of one of the busiest crosswalks in Melbourne, because I wanted to leave my mark as a human being where there seems to be no time and no space to be yourself, and where traces of the body seem to be erased before they can even start to function as traces. I wanted to feel a sense of belonging, to be part of a new city. I wanted to own this new city by dancing in the middle of its streets in an improvised and provoking way. Melbourne CBD was (and still is) a real place for me and the Crosswalk tango performance was the beginning of an informal process of initiation into a more playful and creative way of living it. From the point of view of artistic research, I decided to put my dancing body into the public space out of a desire to explore what tango can be outside the boundaries of the social dance community (dance halls, studios, festivals, etc.) and of its social norms and rituals, ways of dressing and behaving, musical conventions, aesthetic codes, etc. By bringing tango to the new environment of Melbourne's inner streets in a non-traditional improvisational way, I was hoping to find something new about the city and about tango working with both tango and the city as two intertwined learning processes. Indeed, while as a beginner I had experienced tango as a powerful gap in the ap- 
parently unified perception of self, body and world, as time went by I have felt trapped in a new grid of meanings and practices which needed to be untamed. Tango had provoked my sensations and imagination in the first place. Now it was my turn to try to let go of my attachments to the form so that new pathways towards the unknown could be discovered.

\section{Learning from Failures}

How did I feel as a dancer going through the Crosswalk experiment? How did the city-its sounds, images and rules of spatial and temporal engagement-impact on my body, on my movements, on my tango? In retrospective, to put it bluntly, I just could not let the environment creatively affect me-so I don't really have a detailed answer to these questions. But this in itself is an important insight on how the creative process works (or does not work). Through my habitual modes of somatic attention, I could not recognise the fuller sensate-relational field the city was presenting me with, connect with internal impulses and make sense of external inputs. I relate my failure to attune to the city to being nervous and to the fear for uncertainty. There was uncertainty for the illegality of standing in the middle of a crosswalk. Police officers did admonish us to move on a few times: "This is enough, you can't stay here". Were we endangering public safety even though we were not trying to stop people? Was our own safety in danger? Fear was also related to uncertainty about what I was trying to do and how people would judge me-the very choice of bringing my sensibility to the city was under public scrutiny thus putting in question my self-esteem and the worth of my inquiry. Uncertainty pushed me to cling on to the form and patterns of the dance I was most familiar with and the intimacy of the relationship with my partner. The result was a feeling of being caught in external shape.

Noticing and coming to terms with the ephemerality and the constant evolution of my practice is perhaps the key lesson I have learned throughout this project. I engaged an urban exploration of Melbourne streets in search of an alternative to the conventional dynamics of studying and teaching tango in studios and practicing in dance-halls. Through Crosswalk, I learned directly how much extra somatic awareness was needed in trying to let the form emerge through exploration. With the broad term "somatic", I am referring to a first-person approach to inquiry and experience more in general based on the body as an internally sensed and immediately perceived living process of awareness (physical, emotional and cognitive) and of entanglement with the external world (see Hanna 1976, 1985, 1986). Through Crosswalk, I also learned that the city does not necessarily liberate me in my work, but it can also be a restrictive force. I needed to return to the studio and turn the focus of the work outside-in. I needed a space of trust, openness and potential experimentation - not the studio as a social teaching and dancing environment but as an independent peer-to-peer research lab where I can train with other dancers on a range of methods, techniques and perceptual modes of movement inquiry that effectively support the emergence of a plurality of perception and the deepening, widening and heightening of body aliveness (for a practice-based inquiry of some key somatic strategies and tools in the field of dance improvisation, see Fraser 2012).

\section{Crosswalk as Public Pedagogy}

This article is an opportunity to engage my dance-and-performance-based exploration in Melbourne CBD through the conceptual lenses of public pedagogy. In what follows I attempt to pinpoint and ponder on some key learnings emerging out of Crosswalk in terms of recent intellectual debates (for a comprehensive review of the field, see Sandlin et al 2011). Analytically, Crosswalk could be classified as a 'public artistry and performance' 
public pedagogy project-a category which belongs to the broader typology of 'informal institutions and public spaces as sites of public pedagogy' as articulated by Sandlin et al (2011, pp. 348-351). Along these lines, dancing tango in the middle of a pedestrian crossing might work as a 'cultural signifier' which creates 'metaphors that teach the public "common-sense" ways of viewing "reality" (Sandlin et al 2011, p. 349). When watching the video that accompanies this text with this possible reading in mind, the contrast between the intimate stillness of the two dance partners facing each other and the fleeting movement of pedestrians crossing with the green lights becomes more evident. Borrowing from Deleuze and Guattari (2008, esp. pp. 474-476), it is possible to make sense of the Crosswalk experiment as an attempt to 'smooth' the apparently unproblematic reduction of inner city street crossing to a 'striated' space-a space dominated by organising, enveloping and capturing qualities. It is also pertinent to ask whether and how the signifiers and signs of the Crosswalk tango performance were negotiated among dancers, pedestrians and the site. Indeed, we neither talked to pedestrians or give them an option to leave a feedback on whether or how they were affected by the experiment. But this did not occur out of negligence or lack of attention.

The question of how public pedagogical enactments relate with the public brings to the fore the very choice of taking the particular art-form of tango to the streets of Melbourne. This is a choice which reflects my understanding of tango as the performative outcome of long and conflictual processes of public negotiation among different sections of the Argentine population by poetic, musical and bodily means. In particular, tango emerged in Buenos Aires, a place that, between the late 19th century and the early 20th century, was faced with great social and cultural transformations and massive migratory flows from the country and overseas and turned from a big village into a modern multi-ethnic metropolis (Collier et al 1997, esp. ch. 1 on the birth of tango). Tango first developed among a mix of the lower urban and suburban classes of descendants of African slaves, natives of the regions, known as criollos, and European immigrants-especially from Italy, Spain and France. In the brief note announcing its inscription in the UNESCO's Representative List of the Intangible Cultural Heritage of Humanity (1999), tango is described as 'the most recognizable embodiment' of the 'distinctive cultural identity' merging a wide range of customs, beliefs and rituals belonging originally to these three sections of the population. In its traditional form, tango works as a lived event through which the dancers encounter each other in a practiced space, where there are viewers affecting and being affected by the dance, and where tango music is played. The non-verbal negotiation of personal and trans-personal meanings is at the very heart of the tango performance (Cara 2009). This exchange has typically occurred in the quite specific representational setting of Argentina popular culture and national history (Collier 1992; Collier et al 1997) and has often involved the colonial and post-colonial dynamics of exoticism and exploitation (Savigliano 1995).

The pedagogical implications of trying to experience Argentine tango out of its traditional ritualistic context and practices are problematic and stimulating at the same time. I would like to maintain that, the lessons learned by engaging with tango in the middle of a pedestrian crossing in Melbourne CBD can help us defuse the mainstream view of pedagogy as an act in which teaching and learning agents and activation and reception of new meanings are conceived as distinct and separate cognitive entities and mechanisms relatively independent from the environment. This resonates with Burdick and Sandlin's (2013) critique of the humanist/rationalist/modernist model of public pedagogy, which targets 'the Western notion of the self as a developmental, autonomous, and rational iso- 
late, as the object of pedagogical and curricular energies' (p. 145) and continues to rely 'on school-based meanings and mechanisms as heuristic for all sites of education' (p. 146). As I experienced wandering and performing in the city as a kind of 'reverse' public pedagogy, I was not trying to teach something to the public, or to de-institutionalise learning and the public. Rather, I was trying to de-institutionalise myself and my learning and to understand how my relation to the outside world works from a creative practice-based perspective. With Crosswalk, pedagogy is mobilised as a frame to hinge at the unspoken, unarticulated possibility of letting the city emerge as a learning experience of what is not announced, not organised, not regulated, not advertised, not sold, not curated, etc. - that is, of what is improvised in relationship with an embodied-poetic frame. The revealing encounter with my body in Melbourne CBD urges me also to ask what is meant by 'public' both as lived experience and theoretical construct. Drawing on Biesta's interpretation of public pedagogy 'as the enactment of a concern for the public quality of human togetherness' (2012, p. 683), it is possible to look at the Crosswalk autobiographical process of becoming tango also as a pedagogical enactment that opens up the possibility for forms of human exchange which contribute to the becoming public of inner city spaces (a busy crosswalk in this particular instance) by revealing difference and fostering plurality.

\section{Conclusion}

Starting from my autobiographical encounter with Melbourne CBD as an immigrant tango dancer, and drawing on street wandering as an everyday practice of exploration, the Crosswalk performance experiment brings to life the important tension between the suppression of physical sensations that characterises mass culture and built environments in contemporary urban society and the transformative desire to learn how to make sense of our self and of our place in the world in embodied, relational and imaginative terms. No one teaches us how to experience urban dwelling in fulfilling ways. The tango dance in close embrace in the middle of a busy pedestrian crossing works as a reverse public pedagogy: both as a way of coping with the chaos of external inputs and trying to learn how to have a dance with the city; and as a way of seeking a place for my tango and of becoming tango by challenging the restrictive logic of learning, teaching and performing in dance studios and halls in and through controlled and normalised contexts and mechanisms. By putting my improvised tango out there, in the vulnerable space between ego and otherness, homologation and difference, docility and subversion, I can allow people's non-verbal ways of being in publicness to affect by impulses and foster my creativity. Crosswalk is at the same time the kinesthetic enactment of this process of inquiry and its audiovisual exposition.

It is the experience of failure-to let the city affect my creative process from the inside and to become tango in the city - that drives the public pedagogical dimension of Crosswalk (and of tango) to the foreground and that guides the conversation with theoretical frameworks in the field of public pedagogy. The nexus between tango and learning processes and mechanisms is tacit, i.e., it cannot be articulated with words because it emerges out of a non-cognitive bodily engagement with one's perception of movement in the touch-based experience of improvising with someone else (e.g. we learn how to walk together). In this sense, tango is an intimate pedagogical encounter through which the seeds of a kinaesthetic-affective mutual sensitivity are spread and our ways of understanding body, self and world are subtly altered. 


\section{Acknowledgements}

I would like to thank the Institute of Public Pedagogies for the opportunity to present previous developments of my work at their annual conference in 2015 (as a performative talk) and in 2016 (as a movement and dance workshop). The decision to present the site-responsive dance performance Crosswalk as a combination of video and text and to try to frame it in the intellectual context of public pedagogies was driven by attending the Master Class in Public Pedagogy organised by the institute and led by US scholar Jennifer Sandlin on 19-22 June 2017.

I would also like to acknowledge: the continuous support of my supervisors at Deakin University; the collaboration of Ilma Ali (dance partner), Heena Mulchandani (photographs) and Elian Sellanes (music) in the realisation of the Crosswalk performance and video; and the several inspiring conversations with Robert Draffin (Victorian College of the Arts) on the transformative ways in which we can let the city affect us and the creative process.

\section{Video Link}

Raffaele Rufo, 2016, Crosswalk, https://vimeo.com/241816570

\section{References}

Batson, G 2009, 'Somatic studies and dance', <www.iadms.org/page/248> (Accessed 24 August 2017).

Baudelaire, C 1964, The Painter of Modern Life and other Essays, Phaidon Press, London.

Biesta, G 2012, 'Becoming public: Public pedagogy, citizenship and the public sphere', Social \& Cultural Geography, vol. 13, no. 70, pp. 683-697.

Burdick, J \& Sandlin J A 2013, 'Learning, becoming, and the unknowable: Conceptualizations, mechanisms, and process in public pedagogy literature', Curriculum Inquiry, vol. 43, no. 1, pp. 142-177.

Cara. A C 2009, 'Entangled Tangos: Passionate Displays, Intimate Dialogues', The Journal of American Folklore, vol. 122, no. 486, pp. 438-465.

Collier, S 1992, 'The Popular Roots of the Argentine Tango', History Workshop Journal, vol. 34, no. 1, pp. 92-100.

Collier, S, Cooper, A, Azzi, M S \& Martin, R 1997, Tango!: The Dance, the Song, the Story, Thames and Hudson, London.

Deleuze, G \& Guattari, F 2008, A Thousand Plateaus: Capitalism and Schizophrenia, Continuum, London.

De Certeau, M 1988, The Practice of Everyday Life, University of California Press, London.

Fraser, P 2014, Now and Again: Strategies for Truth in Performance, MA research thesis, Monash University, <www.academia.edu/9223802/Now_and_again_strategies_for_ truthful_performance> (Accessed 24 August 2017).

Hanna, T 1976, 'The field of somatics', Somatics: Magazine-Journal of the Bodily Arts and 
Sciences, vol. 1, no. 1, pp. 30-34, <https://somatics.org/library/biblio/htl-fieldofsomatics> (Accessed 24 August 2017)

Hanna, T 1985, Bodies in Revolt: A Primer in Somatic Thinking, Freeperson Press, Novato, California.

Hanna, T 1986, 'What is Somatics? (Part I)', Somatics: Magazine-Journal of the Bodily Arts and Sciences, vol. 5, no. 4, pp. 4-8, <https://somatics.org/library/htl-wis1> (Accessed 24 August 2017).

Kaye, N 2000, Site-specific Art: Performance, Place and Documentation, Routledge, London \& New York.

Kloetzel, M \& Pavlik, C (eds) 2010, Site Dance: Choreographers and the Lure of Alternative Spaces, University Press of Florida, Gainesville.

Nelson, R 2013, Practice as Research in the Arts: Principles, Protocols, Pedagogies, Resistances, Palgrave, New York.

Polanyi, M 2009, The Tacit Dimension, The University of Chicago Press, Chicago \& London.

Sandlin, J A, O’Malley, M P \& Burdick, J 2011, 'Mapping the complexity of public pedagogy scholarship: 1894-2010', Review of Educational Research, vol. 81, no. 3, pp. 338-375.

Savigliano, M 1995, Tango and the Political Economy of Passion, Westview Press, Boulder, Colorado.

UNESCO 2009, 'Nomination and Inscription of Tango on the Representative List of the Intangible Cultural Heritage of Humanity', <www.unesco.org/culture/ich/RL/00258> (Accessed 24 August 2017). 